International scientific and technical conference

DOI: $10.34185 / 1991-7848 . i t m m .2020 .01 .008$

УДК 621.365 .22

\title{
ЕНЕРГОЕФЕКТИВНІ РІШЕННЯ ПОДОВОГО ЕЛЕКТРОДУ ДУГОВОЇ СТАЛЕПЛАВИЛЬНОЇ ПЕЧІ ПОСТІЙНОГО СТРУМУ
}

Тімошенко С.М. д.т.н., с.н.с., Губинський М.В. д.т.н., проф. Донецький національний технічний університет, м. Покровськ Національна металургійна академія України, м. Дніпро

Анотація. Проведено чисельні дослідження електровихрових течій (EBT) в сталеплавильній ванні дугової печі постійного струму i теплопередачі з фазовим переходом через подовий електрод (ПЕ). Щільність теплового потоку в ПЕ і локальна швидкість ЕВТ в анодній ямі становлять 1,8 -2 МВт/м ${ }^{2}$ і 0,75 м/с, відповідно. Рівноважна товщина твердої сталевої частини ПЕ знаходиться в критичній залежності від ширини мідно-сталевої перехідної зони, яка має не перевищувати 20-25 мм. Вдосконалено технологію виготовлення ПЕ з вузькою перехідною зоною, що забезпечує сталу експлуатацію ПЕ та підвищення енергоефективності печі.

Ключові слова: дугова сталеплавильна піч постійного струму, подовий електрод, фазовий перехід, перехідна зона мідь-сталь, енергоефективність.

Вступ. Критичним і недостатньо дослідженим вузлом дугових печей постійного струму (ДСППС) є подовий електрод (ПЕ) , який в умовах електровихрових течій (ЕВT) в рідкій ванні частково розплавляється. Актуальним є дослідження теплового стану ПЕ, що впливає на безпеку експлуатації і енергоефективність печі $[1,2]$. Недостатньо даних щодо величин конвективної й джоулевої складових теплового потоку через ПЕ, ініційованого EBT, впливу характеристик перехідної зони мідь-сталь та інтенсивності охолодження мідної частини стрижня на положення лінії фазового переходу. Розглянуті проблеми особливо стосуються інноваційних «flat bath» сталеплавильних технологій.

Основний матеріал. Тепловий стан ПЕ в циркулюючій сталеплавильній ванні описується критеріальним рівнянням [3]:

$$
\mathrm{Nu}=0,017 \cdot \operatorname{Re}^{0,8} \cdot \operatorname{Pr}^{0,33}
$$


Ministry of Education and Science of Ukraine

The National Metallurgical Academy of Ukraine, Dnipro, 17 - 19 March, 2020

де $\mathrm{Nu}=\alpha_{\mathrm{b}} L / \lambda, \quad \operatorname{Re}=u_{\mathrm{be}} L / v, \quad \operatorname{Pr}=\rho C v / \lambda-$ числа Нуссельта, Рейнольдса, Прандтля; $L$-характерний розмір; $\rho, \lambda, v, C-$ щільність, теплопровідність, кінематична в'язкість, теплоємність рідкої сталі, відповідно. $\alpha_{\mathrm{b}}$ - коефіцієнт конвективної тепловіддачі від ванни до ПЕ; $u_{\mathrm{be}}$ - швикість ЕВТ в зоні ПЕ.

В одномірній постановці стаціонарної задачі теплопередачі щільність теплового потоку через перетин електроду $q_{\mathrm{be}}=q_{\mathrm{b}}+q_{\mathrm{j}}$, Вт $/ \mathrm{M}^{2}$ обумовлена тепловим навантаженням від рухомої ванни $q_{\mathrm{b}}=\alpha_{\mathrm{b}}\left(t_{\mathrm{b}}-t_{\mathrm{m}}\right)$ i через виділення теплоти Джоуля $q_{\mathrm{j}}=U I / F_{\mathrm{be}}$ (де $t_{\mathrm{b}}, t_{\mathrm{m}}$ - температура ванни і плавлення сталі, відповідно; $F_{\mathrm{be}}$-площа перерізу стрижня ПЕ; $U, I$-робочі напруга і сила струму). Величиною $q_{\mathrm{be}}$ визначається залишкова рівноважна товщина твердої сталевої частини $b_{\mathrm{s}}$ (рис. 1a).

$$
b_{\mathrm{s}}=\left[\left[\left(t_{\mathrm{c}}-t_{\mathrm{w}}\right) / q_{\mathrm{be}}\right]-\left(1 / \alpha_{\mathrm{b}}\right)+\left(b_{\mathrm{t}} / \lambda_{\mathrm{t}}\right)+\left(b_{\mathrm{c}} / \lambda_{\mathrm{c}}\right)+\left(1 / \alpha_{\mathrm{w}}\right)\right] \lambda_{\mathrm{s}}
$$

де $t_{\mathrm{c}}, t_{\mathrm{w}}$ - робоча температура міді і води, відповідно; $b_{\mathrm{t}}, \lambda_{\mathrm{t}}, b_{\mathrm{c}}, \lambda_{\mathrm{c}}$-ширина та коефіцієнт теплопровідності перехідної зони і мідної частини ПЕ, відповідно; $\lambda_{\mathrm{s}}-$ коефіцієнт теплопровідності твердої сталевої частини; $\alpha_{\mathrm{w}}-$ коефіцієнт конвективної тепловіддачі від стінки каналу ПЕ до води.

Величина $b_{\mathrm{s}}$ падає зі збільшенням швидкості ЕВТ, і при $u_{\mathrm{be}} \geqslant 0,5 \mathrm{~m} / \mathrm{c}$ стає критично малою, а режим роботи ПЕ - нестабільним (рис. 1б). Внесок $k_{\mathrm{j}}$ джоулєвої складової $q_{\mathrm{j}}$ в загальне теплове навантаження на ПЕ не перевищує $20 \%$. Він зростає з підвищенням струму і падає з ростом $u_{\text {be }}$ (рис. 1в). В сумі $q_{\mathrm{b}}$ та $q_{\mathrm{j}}$ в промисловій ДСППС становить 1-2 МВт/м².

Інтенсифікація охолодження ПЕ понад $\alpha_{\mathrm{w}} \geqslant 20 \mathrm{kBT} /\left(\mathrm{M}^{2} \mathrm{~K}\right)$ практично не впливає на $b_{s}$ (рис. 1г). Визначальний вплив на $b_{s}$ має ширина перехідної зони $b_{\mathrm{t}}$ (iї тепловий опір), він зростає зі збільшенням інтенсивності руху металу $u_{\mathrm{be}}$ (рис. 1д).

В нестаціонарній постановці задачі рівноважна товщина сталевої частини ПЕ досягається за 20-22 хв., а її величина прагне до 20 мм, що відповідає стаціонарній моделі для випадку без перехідної зони (рис. 1б). 
International scientific and technical conference Information Technologies in Metallurgy and Machine building - ITMM 2020
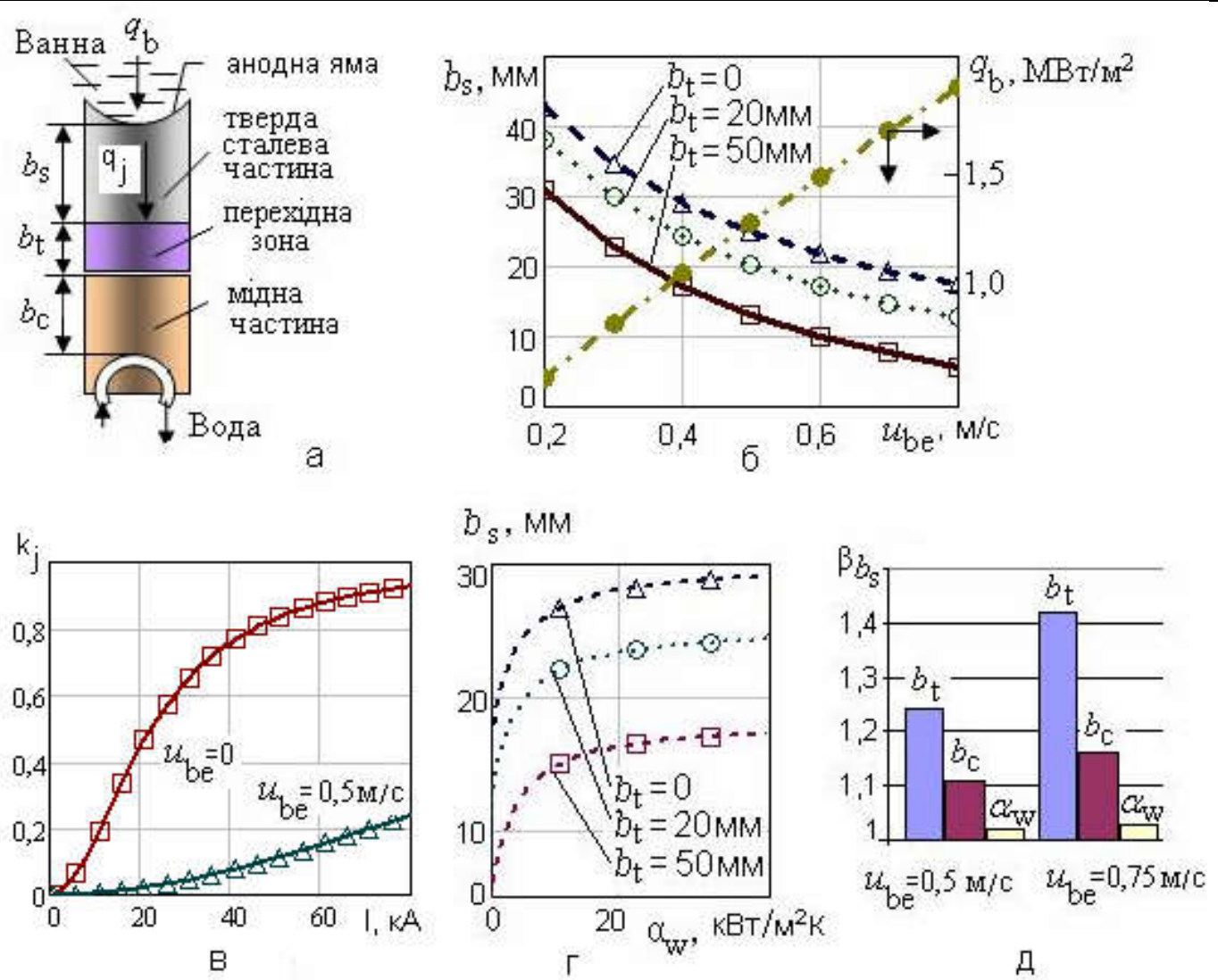

Рисунок 1 - Схема біметалевого ПЕ стрижневого типу (а). Залежність товщини $b_{\mathrm{s}}$ : від швидкості ЕВТ $u_{\mathrm{be}}$ при $b_{\mathrm{c}}=50 \mathrm{мм}, \alpha_{\mathrm{w}}=30 \mathrm{kBT} /\left(\mathrm{M}^{2} \mathrm{~K}\right)\left(\right.$ (б); від $\alpha_{\mathrm{w}}$ при $b_{\mathrm{c}}=50 \mathrm{Mм}$, $u_{\mathrm{be}}=0,5 \mathrm{~m} / \mathrm{c}$ і варіюванні $b_{\mathrm{t}}$ (г). Відносний внесок теплоти Джоуля $k_{\mathrm{j}}$ в залежності від сили струму $I$ при різних $u_{\mathrm{be}}(г)$. Відносна $\left(\beta_{b_{\mathrm{s}}}\right)$ зміна $b_{\mathrm{s}}$ при зниженні $b_{\mathrm{t}}, b_{\mathrm{c}}$ і $\alpha_{\mathrm{w}}$ вдвічі (д)

Оцінку локального значення $u_{\mathrm{be}}$ в анодній ямі проведено шляхом чисельного моделювання ЕВТ, гідродинаміки і теплообміну ванни ДСППС в пакеті «ANSYS CFX» із залученням керуючих рівнянь гідромеханіки: нерозривності, балансу імпульсу (Нав'є-Стокса), дисипації енергії в рамках $k-\varepsilon$ моделі турбулентності; теплопровідності та електродинаміки: Максвелла, узагальненим законом Ома, законом збереження електричного заряду. Результати моделювання свідчать, що в анодній ямі спостерігається максимальна локальна швидкість ЕВТ 0,75 м/с, при якій, згідно з (1) та рис. 1б, щільність теплового потоку конвекції становить 1,8 МВт/м², а з урахуванням джоулевої складової (рис. 1в) - близько 2 МВт/м². Рівноважні характеристики двофазної сталевої частини ПЕ підтверджують критичність умов роботи ПЕ за 
Ministry of Education and Science of Ukraine

The National Metallurgical Academy of Ukraine, Dnipro, 17 - 19 March, 2020

товщиною твердої сталевої частини $b_{\text {s }}$ (рис. 1б), що становить, згідно 3 моделюванням, менш, ніж 50 мм. Одержані дані стосовно теплового стану ПЕ в ДСППС відповідають [2].

Розроблено технологічні основи отримання ПЕ в вузькою перехідною зоною методом двохстадійного електрошлакового наплавлення міді на сталеву заготовку.

Висновки. В промислових умовах щільність теплового потоку, що проходить через ПЕ в анодній ямі, становить 1,8 -2 МВт/м², а максимальна локальна швидкість ЕВТ сягає 0,75 м/с. В даних умовах рівноважна товщина твердої сталевої частини ПЕ знаходиться в критичній залежності від ширини мідносталевої перехідної зони, яка має не перевищувати 20-25 мм. Внесок джоулевої складової в загальне теплове навантаження на ПЕ не перевищує 20 \%. Інтенсифікація водоохолодження при коефіцієнті тепловіддачі більш, ніж 20 кBт/( $\left.\mathrm{M}^{2} \mathrm{~K}\right)$ практично не впливає на товщину твердої сталевої частини ПЕ.

Вдосконалено технологію виготовлення ПЕ 3 перехідною зоною 3 шириною, що не перевищує 20-25 мм і забезпечує умови сталої експлуатації i, тим самим, підвищення енергоефективності ДСППС.

\section{References}

1. Lupi, S. (2017). Fundamentals of Electroheat: Electrical Technologies for Process Heating. () Springer International Publishing Switzerland. 620p.

2. Liu, X., Zhou, J., Shi, H. et al. (2008). Melting mechanism of Water-cooled billet-type bottom electrode of direct current arc furnace: a numerical approach. Metallurgical and materials transactions, vol. 39B, 10, 713-724.

3. Kawakami, M., Takatani, R, Brabie, L. (1999). Heat and Mass Transfer Analysis of Scrap Melting in Steel Bath. Tetsu to Hagane, vol. 85, 9, 658-665.

\section{ENERGY EFFICIENT SOLUTIONS OF DC ELECTRIC ARC FURNACE BOTTOM ELECTRODE}

Timoshenko Serhii, Gubynskyi Mykhailo

Annotation. Numerical studies of electrovortex flows (EWF) in the steelmaking bath of DC electric arc furnace and heat transfer with a phase transition through bottom electrode $(\mathrm{BE})$ were carried out. The heat flux density through $\mathrm{BE}$ 
International scientific and technical conference

Information Technologies in Metallurgy and Machine building - ITMM 2020

and local EVF velocity in anode well are $1.8-2 \mathrm{MW} / \mathrm{m}^{2}$ and $0.75 \mathrm{~m} / \mathrm{s}$, respectively. The equilibrium thickness of solid steel BE part is critically dependent on the width of copper-steel transition zone, should not exceed 20-25 mm. Manufacturing technology of BE with a narrow transition zone, which ensures stable operation and increases energy efficiency of the furnace, has been improved.

Keywords: DC ELECTRIC ARC FURNACE, ELECTROVORTEX FLOWS, BOTTOM ELECTRODE, PHASE TRANSITION, COPPER-STEEL TRANSITION ZONE, ENERGY EFFICIENCY. 